\title{
EFFECT OF FACETAL JOINT MOBILIZATION IN LUMBAR SPONDYLOSIS
}

\author{
VIVEK BHANUSHALI*, VAISHALI JAGTAP, POOVISHNU DEVI T
}

Department of Musculoskeletal Sciences, Krishna College of Physiotherapy, KIMSDU, Karad, Maharashtra, India. Email: vivekbhanushali88@gmail.com

Received: 14 February 2016, Revised and Accepted: 18 March 2017

ABSTRACT

Objectives: Lumbar spondylosis is described as a degenerative condition whose symptoms recur over a period of time. Hence, the objective of this study is to find out the effect of transcutaneous electrical nerve stimulation (TENS) and mechanical intermittent lumbar traction (MILT) (conventional therapy) with or without facetal joint mobilization in lumbar spondylosis for speedy and long-term recovery.

Method: A total of 60 subjects clinically diagnosed with lumbar spondylosis of age between 40 and 60 years were recruited and divided into two groups (Groups A and B) with baseline treatment of TENS and MILT given to both groups and facetal joint mobilization along with baseline treatment given to the study group. Pre- and post-intervention outcome were measured using visual analog scale (VAS) for pain and modified Schobers test (MST) for a range of motion.

Result: Results showed extremely significant improvement in VAS and MST score in Group A.

Conclusion: Facetal joint mobilization along with TENS and MILT is effective in relieving pain and improving range of motion in lumbar spondylosis.

Keywords: Lumbar spondylosis, Facetal joint mobilization, Visual analog scale, Modified Schobers test.

(C) 2017 The Authors. Published by Innovare Academic Sciences Pvt Ltd. This is an open access article under the CC BY license (http://creativecommons. org/licenses/by/4. 0/) DOI: http://dx.doi.org/10.22159/ajpcr.2017.v10i6.17716

\section{INTRODUCTION}

Spondylosis refers to degenerative changes in the spine such as bone spurs and degenerating intervertebral discs. Lumbar spondylosis is a common condition described as a degenerative process affecting the discs, vertebral bodies and associated joints of the lumbar vertebrae. The joints most commonly affected are weight-bearing joints, such as feet, knees, hips, and spine [1].

Symptoms are often first reported between the age of 20 and 60 years. Over $80 \%$ of people over the age of 40 years have evidence of spondylosis on X-ray studies [2]. Spondylosis causes pain in the back. Pain is an unpleasant sensory and emotional experience often associated with actual or potential tissue damage (ligaments, disc) [3].

Research was conducted by Verma and Goyal who studied the pain, the range of motion and back strength in chronic mechanical low back pain before and after lumbar mobilization. They concluded that lumbar mobilization along with the exercises for the management of patients with chronic mechanical low back pain, who responded favorably to the intervention [4]. Another research was conducted by Fritz and Lindsay on a single blinded randomized clinical trial to identify a subgroup of patients with low back pain who were likely to respond favorably to an intervention including mechanical traction. In the experimental group, the subjects received 2 weeks of traction and extension oriented exercises, and the control group received only extension oriented exercises. Outcomes were measured by Oswestry disability index. Results suggested that there was no significant difference between the groups. They concluded that a subgroup of patients likely to benefit from mechanical traction may exist [5]. Spondylosis being a degenerative process does not have a good prognosis. Hence, the aim of this study is to find out the effectiveness of facetal joint mobilization in lumbar spondylosis along with conventional treatment such as transcutaneous electrical nerve stimulation (TENS) and mechanical intermittent lumbar traction (MILT). This study is first of its kind focussing on prolonged and speedy recovery of the subjects.

\section{METHODS}

Ethical clearance was obtained from KIMSDU institutional review board. 60 Subjects clinically and radiologically diagnosed with lumbar spondylosis willing to participate were recruited for this study. Informed consent was taken from the subjects. Inclusion criteria were (1) gender-both, (2) age - 40-60 years. Exclusion criteria were low back pain due to tumor, acute ligament injury, fractures, lumbar spine surgery, osteoporosis, recent spine injuries, and radiculopathy. Outcome measure for assessment of pain was visual analog scale (VAS) $[6,7]$ and for the spinal movement was modified Schober's test (MST) [8]. Two groups were formed.

Group A (study group) - Facetal joint mobilization, TENS and MILT.

Group B (control group) - TENS and MILT. Both groups were treated with low TENS 50-100 Hz (sweep mode) for 10 minutes intensity according to tolerance of individual and MILT with traction weight: $1 / 3^{\text {rd }}$ body weight, hold- relax time $-20 / 5$ seconds for 15 minutes $[9,10]$. Group A was treated with baseline treatment along with facetal joint mobilization was therapist uses their body weight to apply a posteroanterior force to the selected spinous process by leaning their body over their arms and performing rocking movements to provide oscillatory movements of the vertebra. The direction of applied force was downward and oscillations for 30 seconds were given for each lumbar vertebrae mobilization [11].

Subjects in both groups were evaluated pre- and post-treatment using VAS for pain and MST for a range of motion of the spine.

\section{Statistical analysis}

Statistical analysis was performed manually as well as using the statistics software INSTAT so as to verify the results derived. $\mathrm{p} \leq 0.01$ was considered statistically significant and $\leq 0.0001$ was considered extremely significant. The statistical analysis of non-parametric data (VAS and MOLBPDI scores) was done by Wilcoxon matched pairs test and Mann-Whitney test. Wilcoxon matched pairs test was used for 
statistical analysis of pre- and post-intervention within the group. Mann-Whitney test was used for between the group analysis (pre-pre and post-post-intervention). The statistical analysis of the parametric data was performed using paired $t$ and unpaired $t$-tests. Student's paired t-test was used for statistical analysis of pre- and post-intervention within the group. Student's unpaired t-test was used between group statistical analysis of Groups A and B.

\section{RESULTS}

A total 60 subjects were taken for study. The gender ratio of Group A was 15:15 (15 males and 15 females) and Group B was 14:13 (14 males and 16 females) and was statistically not significant. Therefore, both groups are matched with respect to gender.

1. Age of the participants in the study was between 40 and 60 years. The mean age of the participants in Group A was 53.1 \pm 5.237 , and the mean age of participants in Group B was 53.1 \pm 4.678 . The difference in the mean age of two groups was statistically not significant $(\mathrm{p}=0.94)$ (Table 1).

2. In this study, pre-interventional mean of VAS score was $7.61 \pm 1.135$ in Group A and 7.74 \pm 0.9936 in Group B whereas post-interventional mean of VAS score was $2.47 \pm 0.770$ in Group A and $6.41 \pm 0.9443$ in Group B. Intragroup analysis of VAS score revealed statistically significant reduction in pain post-interventionally for both groups Group A $(\mathrm{p}<0.0001)$ and Group B $(\mathrm{p}<0.0001)$. Preintervention analysis showed no significant difference between Groups A and B ( $p=0.6951)$. Post-intervention analysis showed the extremely significant difference between Groups A and B $(\mathrm{p}=<0.0001)$ (Table 2).

3. In this study, pre-interventional mean of the MST was $2.826 \pm 0.628$ in Group A and 2.893 \pm 0.6518 in Group B, whereas post-interventionally mean of the MST was $4.33 \pm 0.5622$ in Group A and $3.20 \pm 0.6214$ in Group B, respectively. Intragroup analysis of the MST revealed statistically improvement in flexion range of motion postinterventionally for both groups Group A $(\mathrm{p}<0.0001)$ and Group B $(p<0.0001)$. Pre-intervention analysis showed no significant difference between Groups A and B ( $\mathrm{p}=0.6881)$. Post-intervention analysis showed the extremely significant difference between Groups A and B $(\mathrm{p} \leq 0.0001)$ (Table 3).

\section{DISCUSSION}

A total of 60 subjects clinically diagnosed with lumbar spondylosis and fulfilling inclusion and exclusion criteria with age between 40 and 60 years were included in this study. Convenient sampling with random allocation was used to divide the subjects into two groups with 30 subjects in each group (Groups A and B). Baseline treatment of TENS and MILT was same for both groups whereas Group A was given facetal joint mobilization along with baseline treatment. The outcome was measured using a VAS for pain and modified Schobers scale for a range of motion.

Our study states that lumbar spondylosis is more prevalent in the age group of 50-55 years which supports the previous study which states that over $80 \%$ of people over the age of 40 years have evidence of spondylosis on X-ray studies.

The mean age of the participants in Group A was 53.1 \pm 5.237 and in Group B was $53.1 \pm 4.678$. There was no significant difference between the mean ages of the participants in both groups. Out of the total number of subjects Group A included 15 males and 15 females, and Group B included 14 males and 16 females. Pre-interventional mean of VAS score of Group A was 7.61 \pm 1.135 and Group B was 7.74 \pm 0.9936 . Post-interventional mean of Group A was $2.47 \pm 0.7700$ and in Group B was $6.41 \pm 0.9443$. Intergroup analysis of VAS score was performed using Mann-Whitney test. Pre-intervention analysis showed no significant difference between Groups A and B ( $\mathrm{p}=0.6951)$. Post-intervention analysis showed the extremely significant difference between Groups A and B $(\mathrm{p}<0.0001)$. Pre-interventional mean of MST score was $2.826 \pm 0.6280$ in Group A and 2.826 \pm 0.6280 in Group B and postinterventional mean was $4.33 \pm 0.5622$ in Group A and $3.20 \pm 0.6214$ in
Table 1: Baseline characteristics of participants

\begin{tabular}{lll}
\hline Variable & Group A & Group B \\
\hline Sex & $\mathrm{M}=15$ and $\mathrm{F}=15$ & $\mathrm{M}=14$ and $\mathrm{F}=16$ \\
Age (years) & $53.1 \pm 5.237$ & $53.1 \pm 4.678$ \\
\hline
\end{tabular}

Table 2: Comparison of VAS score

\begin{tabular}{llll}
\hline Group & \multicolumn{2}{l}{ Mean \pm SD } & p value \\
\cline { 2 - 3 } & Pre & Post & \\
\hline A & $7.61 \pm 1.135$ & $2.47 \pm 0.7700$ & $<0.0001^{* *}$ \\
B & $7.74 \pm 0.9936$ & $6.41 \pm 0.9443$ & $<0.0001^{* *}$ \\
p value & 0.6951 & $<0.0001$ & \\
\hline
\end{tabular}

**Extremely significant ( $\mathrm{p} \leq 0.0001)$. VAS: Visual analog scale, SD: Standard deviation

Table 3: Modified Schobers test

\begin{tabular}{llll}
\hline Group & Mean \pm SD & & p value \\
\cline { 2 - 3 } & Pre & Post & \\
\hline A & $2.826 \pm 0.6280$ & $4.33 \pm 0.5622$ & $<0.0001^{* *}$ \\
B & $2.893 \pm 0.6518$ & $3.20 \pm 0.6214$ & $<0.0001^{* *}$ \\
p value & 0.6881 & $<0.0001$ & \\
\hline
\end{tabular}

SD: Standard deviation, ${ }^{* *} \mathrm{p}<0.0001$

Group B, respectively. Intergroup analysis of MST score was performed using Mann-Whitney test. Pre-intervention analysis showed no significant difference in ROM between Groups A and B ( $p=0.6881)$. Post-intervention analysis showed the extremely significant difference between Groups A and B ( $\mathrm{p}<0.0001)$.

The above results correlate with the previous studies in which spinal mobilization is described in terms of improving mobility in areas of the spine that are restricted. Such restriction may be found in joints, connective tissues or muscles. Using mobilization technique the restriction is removed, the source of pain is reduced and the patient experiences symptomatic relief [12]. Gentle mobilization is used for pain relief while more forceful, deeper mobilization is effective for decreasing joint stiffness. TENS is a method of electrical stimulation which primarily aims to provide a degree of symptomatic pain relief by exciting sensory nerves and thereby stimulating either the pain gate mechanism and/or the opioid system. The different methods of applying TENS relate to the different physiological mechanisms [13]. Traction improves signs and symptoms by both biochemical effects that are separation of the intervertebral motion segment [14] and neurophysiological effects that are modulation of nociceptive input in either the ascendingor descending pathways [15]. Combined effect of these interventions helped in the better prognosis of the subjects.

Hence, above results showed that subjects treated with facetal joint mobilization along with TENS and MILT showed better pain relief on VAS and MST as compared to the other group of subjects.

\section{CONCLUSION}

This study provides evidence to support the use of both conventional therapy and facetal joint mobilization in relieving pain and improving range of motion with lumbar spondylosis. In addition, results supported that facetal joint mobilization was more effective along with conventional treatment instead of conventional treatment alone in relieving pain and improving range of motion with lumbar spondylosis.

\section{ACKNOWLEDGMENT}

We acknowledge the guidance and constant support of Dr. G Varadharajulu, Dean, Faculty of Physiotherapy, Karad. Dr. Vaishali Jagtap and Dr. S V Kakade for help in statistical analysis. 


\section{REFERENCES}

1. Patwardhan SK, Bodas KS, Gundewar SS. Coping with arthritis sing safer herbal options. Int J Pharm Pharm Sci 2010;2:1-11.

2. Harsulkar SG, Khatri SM. Effectiveness of Gong's mobilization in cervical spondylosis: A prospective comparative study. Int J Community Med Public Health 2015;2(1):38-44.

3. Thakur S, Srivastava N. An update on neuropathic pain models. Int J Pharm Pharm Sci 2016;8(6):11-6.

4. Verma Y, Goyal M. Pain, range of motion and back strength in chronic mechanical low back pain before and after lumbar mobilisation. Int J Physiother Res 2013;1(3):48-57.

5. Fritz JM, Lindsay W. Results of a randomized clinical trial and subgrouping analysis. Is there a subgroup of patients with low back pain likely to benefit from mechanical traction? Spine 2007;32(26):E793-800.

6. Bijur PE, Silver W, Gallagher EJ. Reliability of the visual analog scale for measurement of acute pain. Acad Emerg Med 2001;8(12):1153-7.

7. Jagtap V, Shanmugam S. Effect of mechanical traction in osteoarthritis knee. Int J Sci Res 2014;3(10):440-3.

8. Boonstra AM, Schiphorst Preuper HR, Reneman MF, Posthumus JB,
Stewart RE. Reliability and validity of the visual analogue scale for disability in patients with chronic musculoskeletal pain. Int J Rehabil Res 2008;31(2):165-9.

9. Lee RY, Evans JH. Loads in the lumbar spine during traction therapy. Aust J Physiother 2001;47:102-8

10. Heijden V, Beurskens A, Dirx M, Bouter LM, Lindeman E. A pilot study to compare the effect of high-dose continuous lumbar traction and low-dose continuous lumbartractionon the magnitude and rate of recovery for patients with low back pain. Phys Ther 1995;81:29-35.

11. Hanrahan S, Van Lunen BL, Tamburello M, Walker ML. The short-term effects of Joint mobilizations on acute mechanical low back dysfunction in collegiate athletes. J Athl Train 2005;40(2):88-93.

12. Jackson RP, Jacobs RR, Montesano PX 1988 Volvo award in clinical sciences. Facet joint injection in low-back pain. A prospective statistical study. Spine (Phila Pa 1976) 1988;13:966-71.

13. Johnson M. TENS. In: Watson. T, editor. Electrotherapy: Evidence Based Practice. Edinburgh: Elsevier; 2008

14. Twomey LT. Sustained lumbar traction. An experimental study of long spine segments. Spine (Phila Pa 1976) 1985;10:146-9.

15. Watkins LR, Mayer DJ. Organization of endogenous opiate and nonopiate pain control systems. Science 1982;216:1185-92. 